\title{
PEMBUATAN KWH METER DIGITAL 1 FASA BERBASIS ARDUINO MEGA 2560
}

\author{
Muhammad Gifar Afria B, Heru Winarno \\ Program Studi Diploma III Teknik Elektro \\ Sekolah Vokasi Universitas Diponegoro
}

\begin{abstract}
Muhammad Gifar Afria B, Heru Winarno, in general, a digital $k$ Wh meter that can be used to monitor the cosphi value is a 3 phase $k W h$ meter. For 1 phase $k W h$ meters it can only be used to monitor voltage and load usage. In this tool a 1 phase digital $\mathrm{kWh}$ meter prototype is made that can be used to monitor cosphi. Cosphi can be compared by comparing voltage and current signals using LM 393 IC. The reading results from IC LM 393 are compared with EX-OR IC so that high signal is obtained when voltage and current have phase difference only. The output of the EX-OR IC is inserted into Arduino to be read and calibrated so that it can be displayed on the $L C D$. for the process of reading the current magnitude used ACS 712 current sensor, while for the voltage sensor reading step down transformer is used with the principle of voltage divider. In this system, the Arduino MEGA 2560 microcontroller is used as a sensor reading processor that is programmed using the $C++$ language so that it can be displayed on a 16x4 LCD. This digital KWH is also equipped with overcurrent protection using a $5 \mathrm{vdc}$ relay that is set to work with a driver in the form of an NPN transistor program on Arduino MEGA 2560. In its appearance this tool can provide information in the form of current, voltage, cosphi and the amount of power used in units of time and has been converted into units of rupiah. This tool can help read electrical instrumentation for homes that are still using analog KWH meters. In the process of measuring this device has an error rate of $0 \%$ for current reading, 0.4 for voltage reading, 0.07 for cosphi reading and $4.5 \%$ for $k W h$ reading.
\end{abstract}

Keywords: ACS 712 sensor, Arduino MEGA 2560, 1 phase digital KWH meter, Cosphi comparator, IC LM 393, IC $E X-O R$

\section{PENDAHULUAN \\ Latar Belakang}

KWh meter merupakan suatu alat yang digunakan oleh pihak PLN untuk mengukur dan menghitung jumlah pemakaian energi listrik yang digunakan oleh konsumen. KWh meter analog yang ada sejak dulu hanya menampilkan jumlah pemakaian daya yang di tampilkan dalam bentuk angka analog, sementara kWh digital menampilkan sisa $\mathrm{kWh}$ yang dapat kita pakai dalam bentuk tampilan angka di LCD 7 segmen.

KWh meter digital 1 fasa yang ada dan di gunakan oleh konsumen dapat menampilkan tegangan, dan jumlah $\mathrm{kWh}$ baik jumlah pemakaian daya ataupun sisa $\mathrm{kWh}$ yang dapat digunakan . Namun kWh digital 1 fasa tidak dapat menampilkan cosphi dan jumlah beban yang digunakan . Cosphi merupakan satuan tenaga listrik yang berpengaruh pada kualitas listrik yang di gunakan oleh konsumen. Semakin besar faktor daya / cos Phi, maka semakin kecil arus listriknya sehingga rugirugi saluran semakin kecil. Jumlah Kwh per bulan semakin kecil, sehingga biaya listrik per bulan semakin kecil. Maka dari itu cosphi juga perlu di tampilkan pada suatu kWh digital 1 fasa.

Pemakaian beban juga erat hubunganya dengan kualitas listrik, namun hal ini merupakan tanggung jawab pada pihak konsumen. Konsumen harus memperkirakan berapa beban maksimal yang di gunakan untuk menyalakan peralatan elektronik yang ada, jika beban yang di gunakan melebihi batas maksimal, maka akan terjadi trip pada instalasi.
Penulis mencoba membuat alat pengukur daya $(\mathrm{kWh})$ meter digital yang tidak hanya menampilkan tegangan, dan kWh tetapi juga dapat menampilkan cosphi dan arus atau beban listrik. KWh ini juga dilengkapi alarm pemakaian beban untuk menghindari trip pada instalasi akibat kelebihan beban. Namun kWh ini tidak seperti kWh yang dapat diisi token pulsa seperti yang dimiliki PLN.

\section{Pembatasan Masalah}

Yang menjadi permasalahan yaitu:

- Arduino Mega 2560 digunakan sebagai mikrokontroller pengendali.

- Sensor tegangan menggunakan prinsip pembagi tegangan

- IC ACS 712 sebagai sensor arus.

- Rangkaian Power supply sebagai supply rangkaian dan arduino.

- Rangkaian komparator cosphi menggunakan IC LM 393.

- Perancangan alat ini tidak membahas Arduino Mega 2560 secara mendalam.

\section{Transformator}

Transformator sesuai dengan gambar 1 adalah suatu peralatan listrik yang dapat memindahkan dan meneruskan energi listrik dari satu atau lebih rangkaian listrik ke rangkaian listrik yang lain melalui gandengan magnet yang berdasarkan prinsip induksi elektromagnet. Penggunaan Transformator dalam sistem tenaga memungkinkan terpilihnya tegangan yang sesuai 
dan ekonomis untuk setiap keperluan. Dalam bidang elektronika transformator digunakan antara lain untuk gandengan impedansi antara sumber dan beban, untuk memisahkan rangkaian satu dengan dengan yang lain ${ }^{[1]}$

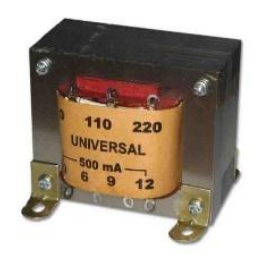

\section{Gambar 1. Transformator[1]}

Prinsip kerja transformator adalah bekerja berdasarkan prinsip induksi elektromagnetik. Tegangan masukan bolak-balik yang membentangi primer menimbulkan fluks magnet yang idealnya semua bersambung dengan lilitan sekunder. Fluks bolak-balik ini menginduksikan GGL dalam lilitan sekunder. Jika efisiensi sempurna, semua daya pada lilitan primer akan dilimpahkan ke lilitan sekunder Ketika lilitan primer dihubungkan dengan sumber tegangan AC, maka pada lilitan primer menimbulkan medan magnet (ggl induksi), Medan magnet diperkuat oleh inti besi dan dihantarkan ke lilitan sekunder, sehingga pada ujung-ujung lilitan sekunder akan timbul GGL induksi. Efek ini dinamakan induktansi timbal-balik (Mutual Inductance).

\section{Penyearah (Rectifier)}

Rangkaian penyearah sesuai gambar 2 adalah suatu rangkaian yang terdiri dari dioda yang digunakan untuk mengubah tegangan bolak-balik (ac) menjadi tegangan searah (dc). Rectifier banyak menggunakan transformator step down yang digunakan untuk menurunkan tegangan.[2]

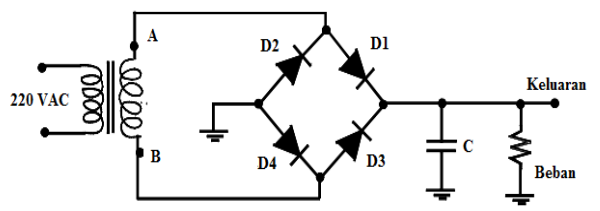

Gambar 2. Penyearah Gelombang Penuh Model Jembatan[2]

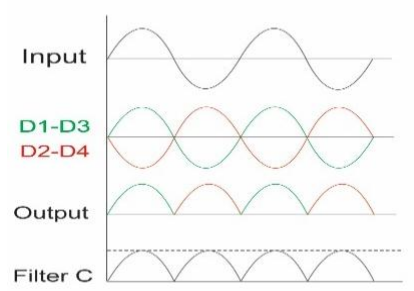

Gambar 3. Gelombang Penyarah Gelombang Penuh Model Jembatan

Pada sistem tenaga listrik tentu Penyearah gelombang penuh model jembatan memerlukan empat buah dioda. Dua dioda akan berkonduksi saat isyarat positif dan dua dioda akan berkonduksi saat isyarat negatif. Untuk model penyearah jembatan ini tidak memerlukan transformator yang memiliki center-tap. Seperti ditunjukkan pada gambar 3 , bagian masukan AC dihubungkan pada sambungan D1-D2 dan yang lainnya pada D3-D4. Katode D1 dan D3 dihubungkan degan keluaran positif dan anode D2 dan D4 dihubungkan dengan keluaran negatif (ground). Misalkan masukan AC pada titik A berharga positif dan B berharga negatif, maka dioda D1 akan berpanjar maju dan D2 akan berpanjar mundur. Pada sambungan bawah D4 berpanjar maju dan D3 berpanjar mundur. Pada keadaan ini elektron akan mengalir dari titik B melalui D4 ke beban , melalaui D1 dan kembali ke titik A. Pada setengah periode berikutnya titik A menjadi negatif dan titik B menjadi positif. Pada kondisi ini D2 dan D3 akan berpanjar maju sedangkan D1 dan D4 akan berpanjar mundur. Aliran arus dimulai dari titik A melalui D2, ke beban, melalui D3 dan kembali ke titik B. Perlu dicatat di sini bahwa apapun polaritas titik A atau B, arus yang mengalir ke beban tetap pada arah yang sama. [2] Setelah keluar dari proses penyarah, kemudian akan masuk ke proses filter yang di lakukan dengan kapasitor untuk menghaluskan gelombang DC.

\section{Sensor Arus Acs 712}

Pengukuran arus biasanya membutuhkan sebuah resistor shunt yaitu resistor yang dihubungkan secara seri pada beban dan mengubah aliran arus menjadi tegangan. Tegangan tersebut biasanya diumpankan ke current transformer terlebih dahulu sebelum masuk ke rangkaian pengkondisi signal. IC ACS712 ditunjukkan oleh gambar 4 .

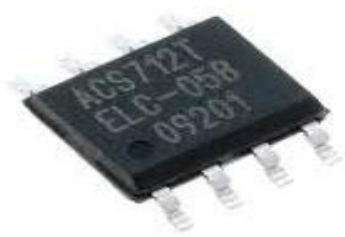

Gambar 4. Acs 712[3]

Teknologi Hall effect yang diterapkan oleh Allegro menggantikan fungsi resistor shunt dan current transformer menjadi sebuah sensor dengan ukuran yang relatif jauh lebih kecil. Aliran arus listrik yang mengakibatkan medan magnet yang menginduksi bagian dynamic offset cancellation dari ACS712. bagian ini akan dikuatkan oleh amplifier dan melalui filter sebelum dikeluarkan melalui kaki 6 dan 7, modul tersebut membantu penggunaan untuk mempermudah instalasi arus ini ke dalam sistem. ACS712 adalah Hall Effect current sensor. Hall effect Allegro ACS712 merupakan sensor yang presisi sebagai sensor arus AC atau DC dalam pembacaan arus didalam dunia industri, otomotif, komersil dan sistem-sistem komunikasi. Pada 
umumnya aplikasi sensor ini biasanya digunakan untuk mengontrol motor, deteksi beban listrik, switched-mode power supplies dan proteksi beban berlebih. Sensor ini memiliki pembacaan dengan ketepatan yang tinggi, karena didalamnya terdapat rangkaian low-offset linear Hall dengan satu lintasan yang terbuat dari tembaga. cara kerja sensor ini adalah arus yang dibaca mengalir melalui kabel tembaga yang terdapat didalamnya yang menghasilkan medan magnet yang di tangkap oleh integrated Hall IC dan diubah menjadi tegangan proporsional. Ketelitian dalam pembacaan sensor dioptimalkan dengan cara pemasangan komponen yang ada didalamnya antara penghantar yang menghasilkan medan magnet dengan hall transducer secara berdekatan. Persisnya, tegangan proporsional yang rendah akan menstabilkan Bi CMOS Hall IC yang didalamnya yang telah dibuat untuk ketelitian yang tinggi oleh pabrik. [3] Output dari sensor ini sebesar (>VIOUT(Q)) saat peningkatan arus pada penghantar arus (dari pin 1 dan pin 2 ke pin 3 dan 4), yang digunakan untuk pendeteksian atau perasa arus. Hambatan dalam penghantar sensor sebesar 1,2 $\mathrm{m} \Omega$ dengan daya yang rendah. Jalur terminal konduktif secara kelistrikan diisolasi dari sensor leads/mengarah (pin 5 sampai pin 8). Hal ini menjadikan sensor arus ACS712 dapat digunakan pada aplikasi-aplikasi yang membutuhkan isolasi listrik tanpa menggunakan opto-isolator atau teknik isolasi lainnya yang mahal. Ketebalan penghantar arus didalam sensor sebesar 3x kondisi overcurrent. Sensor ini telah dikalibrasi oleh pabrik.

\section{IC Komparator LM 393}

Sebuah pembanding (komparator) adalah rangkaian yang berfungsi membandingkan dengan tegangan sinyal input dengan suatu tegangan refrensi. Rangkaian komparator yang sudah di perkenalkan sebelumnya yaitu berupa rangkaian detector yang bersifat open loop dan tegangan inputnya tidak mengalami noise (gangguan). [4] IC LM393 ditunjukkan oleh gambar 5.

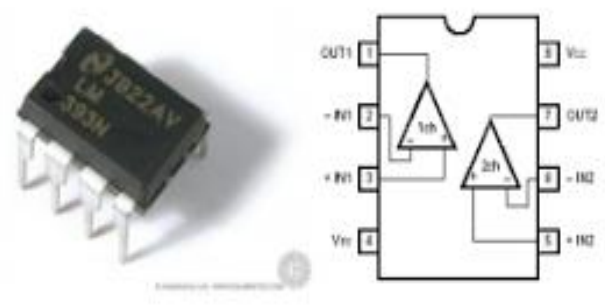

Gambar 5. IC Komparator LM393 [4]

Sesuai dengan sifat op amp sebagai detector maupun komparataor, tegangan output (Vo) di dapatkan dengan adanya tegangan selisih masukan (ed). Jika polaritas Ed adalah positif maka Vo sama dengan +Vsat, demikian juga sebaliknnya., tetapi apabila teganagan inputan $0 \mathrm{~V}$ terkena gangguan noise yang disimbolkna denggan tegnagan noise (En) maka tegangan yang masuk pada kaki inverting input menjadi $(\mathrm{Vi}+\mathrm{Vn})$ sehingga tegangan selisih masukan (Ed) menjadi

$\mathrm{Ed}=0-(\mathrm{Vi}+\mathrm{Vn})=-(\mathrm{Vi}+\mathrm{Vn})$

LM 393 dalam satu kemasannya mempunyai dua buah komparator didalamnya. IC komparator LM 393 memiliki fitur-fitur sebagai berikut:

- Dapat bekerja dengan single supply 2V sampai 36V

- Dapat bekerja dengan tegangan input - 3V sampai +36V

- Dapat bekerja dengan segala macam bentuk gelombang logic

- Dapat membandingkan tegangan yang mendekati ground.

Dalam aplikasinya output dari komparator LM 393, membutuhkan resistor pull up dengan tegangan $\mathrm{V}+$ yaitu untuk menjaga tegangan output supaya memiliki logika satu ketika kondisi diam. Komparator bekerja berdasarkan tegangan yang masuk pada kedua pin inputnya:

- Jika tegangan pada pin(+) lebih besar pada tegangan pin(-) maka output komparator akan bergerak kearah $\mathrm{V}+$.

- Jika tegangan pada pin(+) lebih kecil pada tegangan pin(-) maka output komparator akan bergerak kearah Vdalam aplikasinya biasanya salah satu pin input dari komparator sebagai tegangan referensi sedangkan pin input lainya sebagai tegangan yang akan dibandingkan.

IC LM 393 Digunakan sebagai komparator untuk zero crossing detector yaitu mrmbuat perbandingan antara keluaran sensor tegangan dan sesnsor arus untuk mengetahui besar dari cosphi.

\section{Arduino Mega 2560}

Arduino Mega2560 adalah papan pengembangan microcontroller yang berbasis ATmega2560. Board ini memiliki pin I/O yang cukup banyak, sejumlah 54 buah digital I/O pin (15 pin diantaranya adalah Pulse Width Modulation), 16 pin analog input, 4 pin UART (serial port hardware). Arduino Mega 2560 dilengkapi dengan sebuah oscillator $16 \mathrm{Mhz}$, sebuah port USB, power jack DC, ICSP header, dan tombol reset. Board ini sudah sangat lengkap, sudah memiliki segala sesuatu yang dibutuhkan untuk sebuah microcontroller. Dengan penggunaan yang cukup sederhana, dengan menghubungkan power dari $U S B$ ke $P C$ anda atau melalui adaptor AC/DC ke jack DC. Arduino Mega 2560 ditunjukkan oleh gambar 6 . 


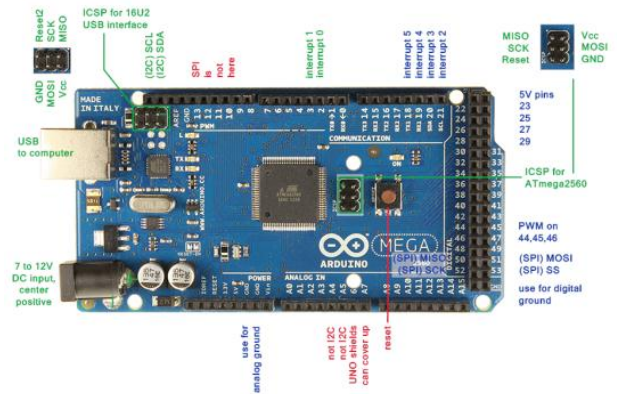

Gambar 6. Board Arduino Mega 2560 [5]

PEMBUATAN KWH METER DIGITAL 1 FASA BERBASIS ARDUINO MEGA 2560

Blok Diagram ditunjukkan oleh gambar 7.

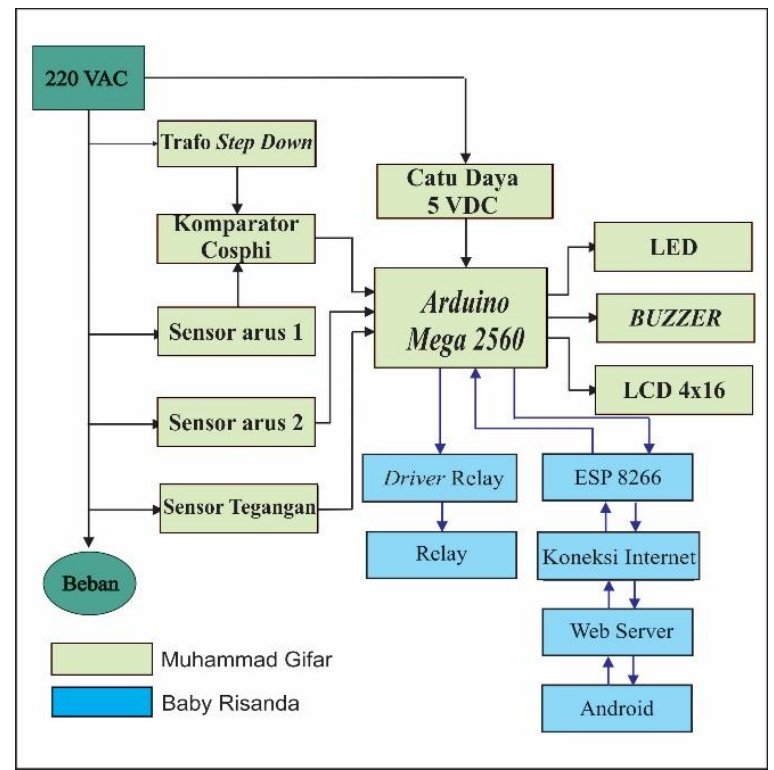

Gambar 7. Diagram Blok

Penjelasan setiap bloknya sebagai berikut:

- Mikrokontroller Arduino Mega 2560 sebagai otak yang akan memproses semua input, output dan otak untuk menjalankan sistem secara keseluruhan.

- Sensor tegangan yaitu berupa trafo tegangan merupakan sensor yang digunakan untuk mengukur tegangan melalui sistem.

- Sensor arus yang menggunakan sensor acs 712 merupakan sensor yang digunakan untuk mengukur besaran arus yang melalui sistem.

- Komparator cos phi merupakan sebuah rangkaian yang digunakan untuk mendeteksi perbedaan sudut fasa dari tegangan dan arus.

- Lcd 16x4 merupakan display yang digunakan untuk menampilkan hasil pengukuran.

- Led digunakan sebagai indikator hidup atau matinya sistem.

- Buzzer digunakan sebagai alarm dalam sistem untuk mencegah overload pemakaian beban.

Pada blok diagram diatas, proses kerja alat dimulai saat sumber tegangan PLN 220 VAC di turunkan menjadi 5 VDC yang di gunakan untuk men-supply Arduino DUE . Rangkaian sensor tegangan di pasang parallel dengan beban dan rangkaian sensor arus di pasang seri dengan beban kemudian output dari sensor arus dan tegangan refrensi yang di hasilkan oleh trafo di gunakan sebagai inputan komparator cosphi. Hasil pembacaan sensor arus, tegangan dan komparator cosphi masuk ke mikrokontroller Arduino DUE untuk diolah dan di tampilkan pada LCD 4 x 16 . Buzzer digunakan sebagai alarm apa bila arus atau beban yang di gunakan telah mencapai titik tertentu. Led digunakan sebagai lampu indikakor nyala atau tidaknya sistem.

\section{Rangkaian Catu Daya}

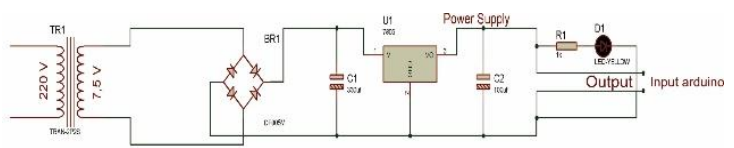

Gambar 8. Schematic Catu Daya

Rangkaian catu daya ditunjukkan oleh gambar 8. Sumber tegangan yang berupa tegangan AC $220 \mathrm{~V}$ diturunkan menggunakan transformator step down sehingga di hasilkan tegangan $\mathrm{AC}$ rendah yaitu sebesar 7,5V. Selanjutnya, Output dari sisi sekunder transformator disearahkan oleh diode berjumlah 4 buah yang berfungsi seperti diode bridge yaitu sebagai rectifier, sehingga di hasilkan output tegangan DC. Kemudian arus yang telah di searahkan belum menjadi arus DC murni. Kapasitor $330 \mathrm{uF}$ digunakan sebagai filter untuk meratakan keluaran dari diode. Dengan menggunakan kapasitor , sinyal-sinyal AC akan ditanahkan, sedangkan sinyal DC akan diteruskan ke IC regulator LM 7805. IC ini digunakan untuk menghasilkan tegangan yang konstan sebesar 5 VDC.

\section{Rangkaian Sensor Tegangan}

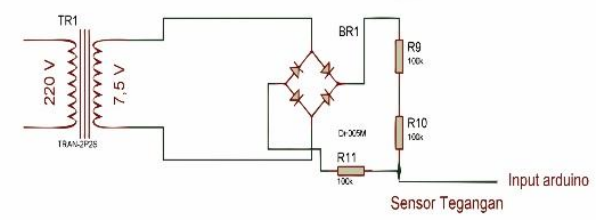

Gambar 9. Rangkaian Sensor tegangan

Rangkaian Sensor tegangan ditunjukkan oleh gambar 9. Tegangan supply PLN di turunkan menjadi tegangan yang lebih rendah yaitu 7,5 VAC yang kemudian di searahkan dengan diode rectifier, sehingga di hasilkan output tegangan DC. Output inilah yang kemudian di turunkan lagi menggunakan rangkaian pembagi tegangan berupa 3 resistor $10 \mathrm{k}$ yang di pasang seri.agar tegangan yang di hasilkan tidak lebih dari 5 V.Tegangan hasil dari pembagi tegangan adalah hasil dari sensor tegangan yaitu 2,5 VDC. Output dari sensor tegangan ini masuk ke pin 0 pada Arduino . 


\section{Rangkaian Sensor Arus ACS712}

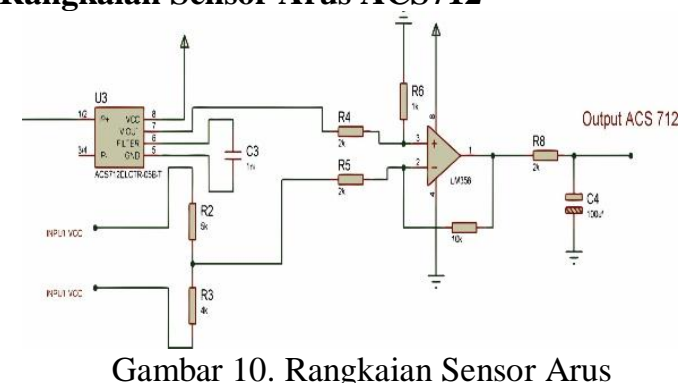

Gambar 10. Rangkaian Sensor Arus

Rangkaian Sensor arus ditunjukkan oleh gambar 10. Pada sistem ini rangkaian sensor arus menggunakan konponen utama yaitu IC ACS 712 5A yang dipasang seri dengan beban. Untuk rangkaian sensor arus dapat di lihat pada lampiran gambar. Keluaran dari sensor ini nilainya adalah 2,5 V. Output dari sensor acs ini berupa sinyal tegangan yang bernilai $185 \mathrm{mV}$ per 1 Ampere karena menggunakan ACS 712 dengan maksimal arus 5A. Jadi artinya setiap kenaikan 1 ampere sinyal tegangan akan naik sebesar $185 \mathrm{mV}$. Jika tidak ada arus yang mengalir maka tegangan akan stabil di 2,5 V. Pada sensor ini di pasang penguat berupa ic LM 358 . LM 358 di rangkai menjadi penguat op-amp diferensial untuk menaikkan sinyal tegangan pada sensor arus sebesar 5 kali nilai nominalnya. Perbedaan tegangan output ACS dan input Sumber dengan pembagi tegangan di kuatkan menjadi 5 kali sesuai perbandingan nilai R1 dan R2. Output dari sensor arus nantinya akan masuk menuju pin ADC mikrokontroller Arduino untuk merubah sinyal analog menjadi sunyal digital agar dapat dibaca dan di tampilkan pada LCD 4 x 16. Output dari rangkaian ini masuk pada pm 1 pada Arduino.

\section{Rangkaian Komparator Cosphi}

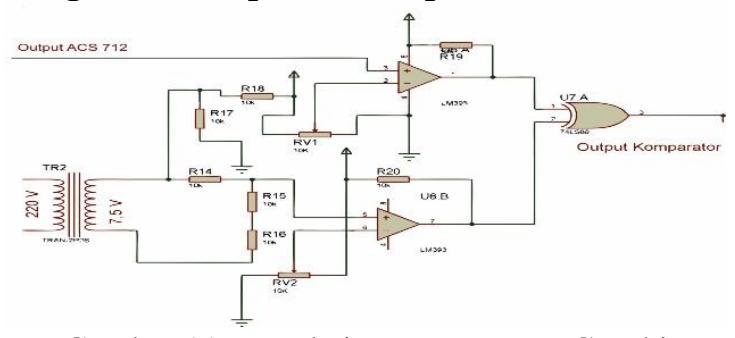

Gambar 11. Rangkaian Komparator Cosphi

Rangkaian komparator cosphi ditunjukkan oleh gambar 11. Pada sistem ini inputan dari rangkaian komparator cosphi ini adalah output dari sensor arus dan tegangan dari transformator. Rangkaian komparator cosphi dapat dilihat pada daftar lampiran gambar. Transformator yang digunakan pada inputan komparator cosphi berbeda dengan yang digunakan pada rangkaian power supply maupun rangkaian sensor tegangan. Fungsi dari rangkaian komparator ini adalah untuk membentuk unputan sinyal AC sinus menjadi outputan sinyal kotak yang dapat dibaca oleh mikrokontroller Arduino. Sifat dari komparator ini adalah membandingkan tegangan input dengan tegangan referensi. Pada komparator tegangan referensinya bernilai $2,5 \mathrm{~V}$. Dimana outputan dari komparator tegangan dan arus adalah frekuensi yang berupa sinyal sinus kotak, maka nilai dari frekuensi input sama dengan frekuensi output, tetapi nilai tegangan input berbeda dengan tegangan output yang berubah menjadi maksimal $5 \mathrm{~V}$ dan berbentuk sinyal kotak agar dapat dibaca oleh Arduino. Output dari komparator tegangan dan komparator arus masuk ke rangkaian EX-OR, dimana outputanya berupa sinyal kotak yang periode outputanya sesuai dengan beda fasa antara sinyal tegangan dan sinyal arus. Jika sinyal tegangan dan sinyal arus tidak terdapat beda fasa maka output EX-OR akan logic 0 , tetapi bila ada perbedaan beda fasa maka outputnya berupa pulsa high low dimana lebar pulsa tergantung pada beda sudut fasa dari sinyal tegangan dan sinyal arus. Perbedaan tersebut . yang akan dihitung melalui program Arduino unruk mengetahui nilai cosphi. Output dari rangkaian cosphi masuk pada pin 2 Arduino.

\section{Flowchart}

Flowchart program ditunjukkan oleh gambar 12.

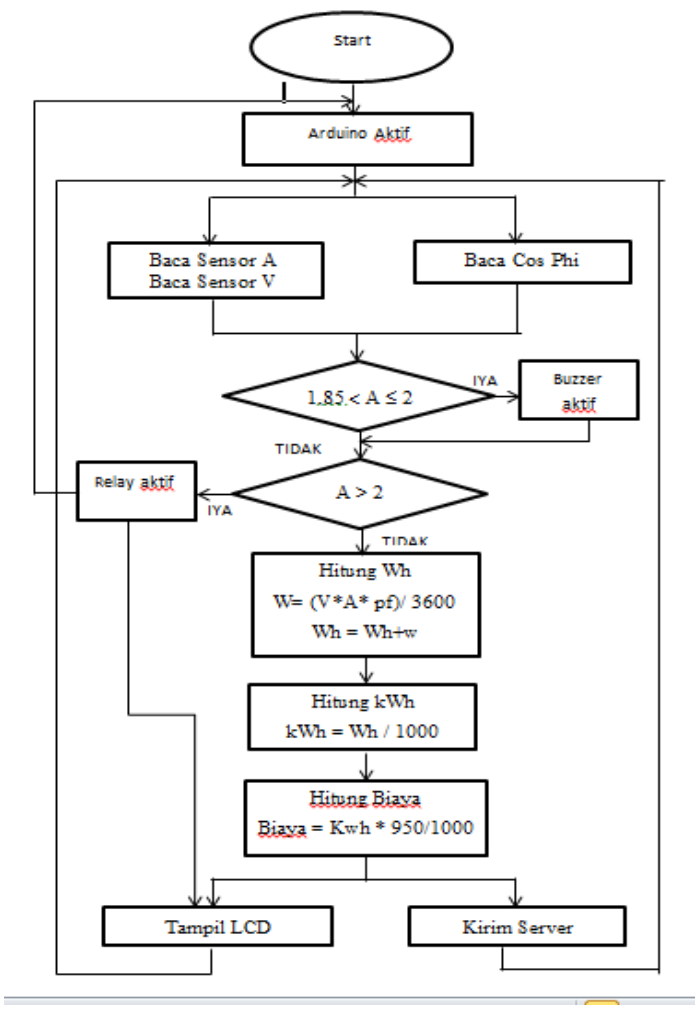

Gambar 12. Flowchart KWh Meter Digital 1 Fasa Berbasis Arduino Mega 2560 
PENGUKURAN DAN PENGUJIAN

Pengukuran Alat

Pengujian tegangan ditunjukkan oleh tabel 1.

Tabel 1. Hasil Pengujian tegangan

\begin{tabular}{lllll}
\hline & \multicolumn{2}{c}{ Tegangan Terukur } & & \\
\cline { 2 - 3 } No & $\begin{array}{c}\text { Multimet } \\
\text { er (VDC) }\end{array}$ & $\begin{array}{c}\text { Tampil } \\
\text { an kWh } \\
\text { 9(VDC) }\end{array}$ & $\begin{array}{c}\text { Selisi } \\
\text { h }\end{array}$ & $\begin{array}{c}\text { Kesalah } \\
\text { an (\%) }\end{array}$ \\
\hline 1 & 221.5 & 220 & 1.5 & 0.5 \\
2 & 221.1 & 220 & 1.1 & 0.4 \\
3 & 221.5 & 221 & 0.5 & 0.2 \\
Rat & 221.3 & 220.3 & 1 & 0.4 \\
a- & & & & \\
rata & & & & \\
\hline
\end{tabular}

Pengujian arus ditunjukkan oleh tabel 2.

Tabel 2. Hasil Pengujian Arus

\begin{tabular}{llcll}
\hline \multirow{2}{*}{$\begin{array}{c}\text { Beba } \\
\mathbf{n}\end{array}$} & $\begin{array}{c}\text { Arus Terukur } \\
\text { ampe } \\
\mathbf{r}(\mathbf{A})\end{array}$ & $\begin{array}{c}\text { Tampila } \\
\mathbf{n} \mathbf{k W h} \\
\mathbf{9}(\mathbf{A})\end{array}$ & $\begin{array}{c}\text { Selisi } \\
\mathbf{h}\end{array}$ & $\begin{array}{c}\text { Kesalaha } \\
\mathbf{n}(\%)\end{array}$ \\
\hline $\begin{array}{l}\text { Lamp } \\
\text { u TL }\end{array}$ & 0.2 & 0.2 & 0 & 0 \\
$\begin{array}{l}\text { 10W } \\
\text { Lamp } \\
\text { u TL }\end{array}$ & 0.07 & 0.07 & 0 & 0 \\
$\begin{array}{l}\text { 15W } \\
\text { Lamp }\end{array}$ & 0.16 & 0.16 & 0 & 0 \\
u TL \\
$\begin{array}{l}\text { 40W } \\
\text { Lamp } \\
\text { u TL }\end{array}$ & 0.24 & 0.24 & 0 & 0 \\
60W & & & & \\
\hline
\end{tabular}

Pengujian cosphi ditunjukkan oleh tabel 3.

Tabel 3. Hasil Pengujian Cosphi

\begin{tabular}{lllll}
\hline \multirow{2}{*}{$\begin{array}{c}\text { Beba } \\
\mathbf{n}\end{array}$} & $\begin{array}{c}\text { Cosphi Terukur } \\
\text { hi } \\
\text { meter }\end{array}$ & $\begin{array}{c}\text { Tampila } \\
\mathbf{n ~ k W h}\end{array}$ & $\begin{array}{c}\text { Selisi } \\
\mathbf{h}\end{array}$ & $\begin{array}{c}\text { Kesalaha } \\
\mathbf{n}(\%)\end{array}$ \\
\hline $\begin{array}{l}\text { Lamp } \\
\text { u TL }\end{array}$ & 0.96 & 0.96 & 0 & 0 \\
$\begin{array}{l}\text { 10W } \\
\text { Lamp } \\
\text { u TL }\end{array}$ & 1 & 0.99 & 0.01 & 1 \\
$\begin{array}{l}\text { 15W } \\
\text { Lamp } \\
\text { u TL }\end{array}$ & 1 & 0.99 & 0.01 & 1 \\
$\begin{array}{l}\text { 40W } \\
\text { Lamp } \\
\text { u TL }\end{array}$ & 1 & 0.99 & 0.01 & 1 \\
60W & & & & \\
\hline
\end{tabular}

Pengujian kwh ditunjukkan oleh tabel 4.
Tabel 4. Hasil Pengujian KWh

\begin{tabular}{|c|c|c|c|c|c|}
\hline $\begin{array}{l}\text { Wak } \\
\text { tu }\end{array}$ & $\begin{array}{l}\text { Beb } \\
\text { an }\end{array}$ & $\begin{array}{l}\text { kW } \\
\text { h } \\
\text { met } \\
\text { er } \\
\text { pln }\end{array}$ & $\begin{array}{l}\text { Pembac } \\
\text { aan } \\
\text { kWh }\end{array}$ & $\begin{array}{l}\text { Selis } \\
\text { ih }\end{array}$ & $\begin{array}{l}\text { Kesala } \\
\text { han } \\
(\%)\end{array}$ \\
\hline $\begin{array}{l}20 \\
\text { meni } \\
t\end{array}$ & $\begin{array}{l}125 \\
W\end{array}$ & $\begin{array}{l}30 \\
W h\end{array}$ & $27.9 \mathrm{Wh}$ & 2.1 & 7 \\
\hline $\begin{array}{l}40 \\
\text { meni } \\
t\end{array}$ & $\begin{array}{l}125 \\
W\end{array}$ & $\begin{array}{l}60 \\
W h\end{array}$ & $\begin{array}{l}57.56 \\
\text { Wh }\end{array}$ & 2.56 & 4.2 \\
\hline $\begin{array}{l}60 \\
\text { meni } \\
t\end{array}$ & $\begin{array}{l}125 \\
W\end{array}$ & $\begin{array}{l}90 \\
\mathrm{Wh}\end{array}$ & $\begin{array}{l}87.82 \\
\text { Wh }\end{array}$ & 2.12 & 2.3 \\
\hline \multicolumn{4}{|c|}{ Rata-rata } & 2.26 & 4.5 \\
\hline
\end{tabular}

\section{KESIMPULAN}

Setelah melakukan perancangan, pembuatan benda kerja dan percobaan, maka penulis dapat memberikan kesimpulan sebagai berikut :

- Arduino Mega 2560 digunakan sebagai pusat pengendali dan juga pembacaan sensor karena memiliki spesifikasi yang baik dan juga memiliki port yang lengkap.

- Sensor tegangan menggunakan prinsip pembagi tegangan yang output teganganya berupa sinyal analog yang dibaca oleh Arduino Mega 2560 dan di konversi menjadi sinyal digital untuk kemudian di kalibrasi dan di tampilkan pada LCD.

- Sensor arus menggunakan IC ACS 712 yang outputnya di kuatkan dengan op-amp diffrensial sebesar 5 kali dan dibaca Arduino Mega 2560 berupa adc untuk kemudian di kalibrasi dan di tampilkan pada LCD.

- Catu daya bermula dari tegangan PLN sebesar 220 VAC yang kemudian diturunkan menggunakan trafo step down menjadi 7,5 vdc untuk kemudian di searahkan. Setelah proses penyearah lalu output di filter menggunakan capasitor dan kemudian di stabilkan teganganya mengguunakan regulator IC 7805. Hasil dari regulator di filter lagi agar menjadi dc murni dengan output 5 VDC.

- Komparator cosphi digunakan untuk membandingkan gelombang dari tegangan dan gelombang arus menggunakan IC LM 393. Perbedaan gelombang tegangan dan arus kemudian di masukkan pada IC EX-OR untuk mendapatkan hasil perbedaan berupa sinyal high untuk kemudian dibaca oleh Arduino Mega 2560.

- Hasil pengukuran tegangan, arus, cosphi dapat digunakan untuk menghitung daya pemakaian. Hasil Pengukuran jika di bandingkan dengan alat ukur dari pabrikan menunjukan memiliki kesalahan rata 3\% untuk Tegangan, 0\% untuk Arus, $0 \%$ untuk Cosphi dan $0,007 \%$, dan untuk Daya $4,5 \%$ 


\section{DAFTAR PUSTAKA}

1. Zuhal. Dasar Teknik Tenaga Listrik Dan Elektronika Daya. Jakarta: PT Gramedia Pustaka Utama, 2000.

2. Dasatrio. Yogi, Dasar-dasar Teknik Elektronika. Yogyakarta : Javalitera, 2015

3. Anonim. ACS 712 (Allegro Current Sensor). Available :https://depokinstruments.com/2012/03/29/senso r-arus-listrik-acs712/ (diakses pada 5 Mei 2017).

4. Anonim. IC LM 393. Available : https://www.onsemi.com/pub/Collateral/LM393 -D.PDF (diakses pada 5 Juli 2017).

5. Anonim. Arduino DUE. Available: https://www.arduino.cc/en/Main/arduinoBoard Due (diakses 5 Mei 2017). 